\title{
The Total Return Swap Pricing Model under Fuzzy Random Environments
}

\author{
Liang Wu, ${ }^{1,2}$ Jun-tao Wang, ${ }^{1}$ Jie-fang Liu, ${ }^{1}$ and Ya-ming Zhuang ${ }^{2}$ \\ ${ }^{1}$ Department of Mathematics, Henan Institute of Science and Technology, XinXiang, Henan 453003, China \\ ${ }^{2}$ School of Economics and Management, Southeast University, Nanjing, Jiangsu 211189, China \\ Correspondence should be addressed to Liang Wu; nidewuliang@163.com
}

Received 8 July 2016; Revised 21 November 2016; Accepted 15 December 2016; Published 24 January 2017

Academic Editor: Pasquale Candito

Copyright (c) 2017 Liang Wu et al. This is an open access article distributed under the Creative Commons Attribution License, which permits unrestricted use, distribution, and reproduction in any medium, provided the original work is properly cited.

\begin{abstract}
This paper models the jump amplitude and frequency of random parameters of asset value as a triangular fuzzy interval. In other words, we put forward a new double exponential jump diffusion model with fuzziness, express the parameters in terms of total return swap pricing, and derive a fuzzy form pricing formula for the total return swap. Following simulation, we find that the more the fuzziness in financial markets, the more the possibility of fuzzy credit spreads enlarging. On the other hand, when investors exhibit stronger subjective beliefs, fuzzy credit spreads diminish. Using fuzzy information and random analysis, one can consider more uncertain sources to explain how the asset price jump process works and the subjective judgment of investors in financial markets under a variety of fuzzy conditions. An appropriate price range will give investors more flexibility in making a choice.
\end{abstract}

\section{Introduction}

Credit derivatives pricing is a mathematical modeling process derived from the real world, where the environment of the existing and dependent markets has various random and fuzzy characteristics. Because the human mind that describes and builds pricing models exhibits uncertainty, the thinking process of mathematical modeling is characterized by randomness and fuzziness. This derives from two sources. On the one hand, as the process of observation and application of statistics is objectively uncertain and inexact, some data will inevitably be erroneous due both to the interference of some objective factors as well as some variables not being accurately estimated. On the other hand, in the process of making market investment decisions, investors will inevitably bring in their subjective judgments, which will also affect the market; this is subjective uncertainty. The market, therefore, contains many uncertain factors and factors affecting the pricing of financial products are not only random, but are also uncertain. Fuzzy theory is a powerful tool to deal with nonrandom uncertainty, but when both randomness and fuzziness are combined, a new "fuzzy random" comes into being. Research into "fuzzy random" provides a new theoretical basis for credit derivatives pricing theory and is a useful and necessary supplement to traditional theory of pure random credit derivative pricing. With this in mind, scholars have begun to use fuzzy random theory in the field of financial pricing and try to use it to describe the fuzziness that appears in the financial product pricing process.

Buckley [1] was the first scholar to introduce fuzzy information into financial analysis. He built a new future value, present value, and internal rate of return into the fuzzy form expression, based on the theory of fuzzy mathematics. He discussed the fuzzy morphology of internal rate of return and constructed a new fuzzy form to describe it. Carlsson and Fullér [2] were the first scholars to introduce fuzzy random analysis into asset pricing, using fuzzy mathematics theory to construct a new "fuzzy" Black-Scholes pricing formula. At the same time they combined it with the fuzzy random properties of real world pricing, deriving the fuzzy real option pricing formula. Muzzioli and Torricelli [3] looked at fuzziness in the amplitude of asset price rises and declines, based on the fuzzy attributes of implied volatility in underlying asset prices, and constructed a fuzzy form expression for a oneor two-stage binomial option tree model. Yoshida et al. [4, 5] discussed the pricing problems of European and American 
financial options by introducing stochastic model fuzzy logic. The literature [6-22], furthermore, discusses the problem of option pricing in fuzzy random environments and has summed up, in recent years [23], the application of fuzzy information to option pricing. Almost all the literature, however, concentrates on option pricing problems; there has been very little work on credit derivative pricing in fuzzy random environments. When E. Agliardi and R. Agliardi [24, 25] first introduced the fuzzy tool into credit risk analysis, they proposed a structural model for defaultable bonds in a fuzzy environment and derived a fuzzy form pricing model for the defaultable bonds. Vassiliou [26] proved that a fuzzy market is viable if and only if an equivalent Martingale measure exists. He described the evolution of credit migration of a defaultable bond as an inhomogeneous semi-Markov process with fuzzy states, and investigated the asymptotic behavior of the survival probability in each fuzzy state given in the absence of default. Wu et al. [27-29] proposed a reducedform intensity-based model under fuzzy environments and presented some applications of this methodology for pricing defaultable bonds and credit default swap (CDS). However, no scholars have considered the total return swap pricing model in a fuzzy random environment, even though this has become a significant problem to be studied.

Inspired by the literature [24, 27], we will combine fuzziness and randomness to study, for the first time, the total return swap pricing problem under fuzzy random environments. Based on the volatility in financial markets, we assume that the value of a reference total return swap credit asset is driven by a double exponential jump diffusion model. Based on the observed existence of fuzziness in market environments, we assume that the magnitude and frequency of asset value jumps are triangular fuzzy numbers. At the same time, in order to consider the effect of interest rate risk on the total return swap pricing, we assume that the market short-term interest rate satisfies the CIR model and fuzzify it as a numerical interval. We then use a structural model to infer the probability of default of the reference asset and finally get the explicit fuzzy form expression of the total return swap pricing model. The advantages of this model lie in the following: Not only can we consider the uncertainty of the value jump diffusion process, but we can also consider the reliability of an investor's subjective judgment of the fuzzy information presented to him in the financial market (the subjective judgment of fuzzy information and the assumption of risk neutral pricing are not in conflict). Meanwhile, an appropriate price range will give investors more flexibility in making a choice and make the model results more precisely representative of the actual market environment.

\section{The Basic Knowledge of Fuzzy Mathematics}

In this section, we review some of the basic concepts of fuzzy mathematics, because these are used in the discussion that follows.

Definition 1 (see [30]). A fuzzy set $\widetilde{A}$ in $R$ is a set of ordered pairs $\widetilde{A}=\{(x, \mu(x)): x \in X\}$, where $\mu(x)$ is the membership function or grade of membership or degree of compatibility or degree of truth of $x \in X$ which maps $x \in X$ on the real interval $[0,1]$.

The $\gamma$-cut of a fuzzy set $\widetilde{A}$ is defined by $\widetilde{A}_{\gamma}=\{x \in$ $R \mid \mu(x) \geq \gamma\}$ for all $\gamma \in[0,1]$. In addition, $\widetilde{A}$ is called a normal fuzzy set if there exists an $x$, such that $\mu_{\widetilde{A}}(x)=1$, and $\widetilde{A}$ is called a convex fuzzy set if $\mu_{\widetilde{A}}(\lambda x+(1-\lambda) y) \geq$ $\min \left\{\mu_{\widetilde{A}}(x), \mu_{\widetilde{A}}(y)\right\}$ for all $\lambda \in[0,1]$. Let $\widetilde{a}$ be a fuzzy subset of $R$, if the following conditions are satisfied: (1) $\widetilde{a}$ is a normal and convex fuzzy set, (2) its membership function $\mu_{\tilde{a}}(x)$ is upper semicontinuous, and (3) the $\gamma$-cut set $\tilde{a}_{\gamma}$ is bounded for each $\gamma \in[0,1]$; then $\tilde{a}$ is called a fuzzy number [31]. According to [16], if $\widetilde{a}$ is a fuzzy number, then its $\gamma$-cut set $\widetilde{a}_{\gamma}$ is a compact and convex set; that is, $\tilde{a}$ is a closed interval in $R$; then the $\gamma$ cut set of $\tilde{a}$ can be denoted by $\tilde{a}_{\gamma}=\left[\tilde{a}_{\gamma}^{-}, \tilde{a}_{\gamma}^{+}\right]$.

A triangular fuzzy number $\widetilde{a}$ with membership function $\mu_{\tilde{a}}(x)$ is defined as follows:

$$
\mu_{\tilde{a}}(x)= \begin{cases}1-\frac{a_{2}-x}{a_{2}-a_{1}}, & \text { if } a_{1} \leq x \leq a_{2}, \\ 1-\frac{x-a_{2}}{a_{3}-a_{2}}, & \text { if } a_{2} \leq x \leq a_{3}, \\ 0, & \text { otherwise. }\end{cases}
$$

Here $\left[a_{1}, a_{3}\right]$ is the supporting interval and the membership function has peak in $a_{2}$. A triangular fuzzy number $\tilde{a}$ is denoted by $\tilde{a}=\left(a_{1}, a_{2}, a_{3}\right)$. The $\gamma$-cut set of $\tilde{a}$ is described as $\tilde{a}_{\gamma}=\left[a_{2}-(1-\gamma) a_{1}, a_{2}+(1-\gamma) a_{3}\right]$.

Ref. [32] discussed the arithmetic of any two fuzzy numbers. Let "." be a binary operator,,$+- \times, /$, between two fuzzy numbers $\widetilde{a}$ and $\widetilde{b}$. The membership function of $\widetilde{a} \cdot \widetilde{b}$ is given by $\mu_{\widetilde{a} \cdot \tilde{b}}=\sup _{\{(x, y) \mid x \circ y=z\}} \min \left\{\mu_{\tilde{a}}(x), \mu_{\tilde{b}}(y)\right\}$.

Proposition 2 (see [32]). Let $\tilde{a}$ and $\tilde{b}$ be two fuzzy numbers, and $\tilde{a}_{\gamma}=\left[\widetilde{a}_{\gamma}^{-}, \tilde{a}_{\gamma}^{+}\right]$and $\tilde{b}_{\gamma}=\left[\widetilde{b}_{\gamma}^{-}, \tilde{b}_{\gamma}^{+}\right]$. Then $\tilde{a}+\widetilde{b}, \widetilde{a}-\widetilde{b}$, and $\tilde{a} \times \tilde{b}$ are also the fuzzy numbers and their $\gamma$-cut sets are given by $(\widetilde{a}+\widetilde{b})_{\gamma}=\left[\widetilde{a}_{\gamma}^{-}+\widetilde{b}_{\gamma}^{-}, \tilde{a}_{\gamma}^{+}+\widetilde{b}_{\gamma}^{+}\right],(\widetilde{a}-\widetilde{b})_{\gamma}=\left[\widetilde{a}_{\gamma}^{-}\right.$ $\left.\tilde{b}_{\gamma}^{+}, \tilde{a}_{\gamma}^{+}-\tilde{b}_{\gamma}^{-}\right]$, and $(\tilde{a} \times \tilde{b})_{\gamma}=\left[\min \left\{\widetilde{a}_{\gamma}^{-} \widetilde{b}_{\gamma}, \tilde{a}_{\gamma}^{-} \tilde{b}_{\gamma}^{+}, \tilde{a}_{\gamma}^{+} \widetilde{b}_{\gamma}^{-}, \tilde{a}_{\gamma}^{+} \tilde{b}_{\gamma}^{+}\right\}\right.$, $\left.\max \left\{\widetilde{a}_{\gamma}^{-} \widetilde{b}_{\gamma}^{-}, \widetilde{a}_{\gamma}^{-} \widetilde{b}_{\gamma}^{+}, \tilde{a}_{\gamma}^{+} \widetilde{b}_{\gamma}, \tilde{a}_{\gamma}^{+} \widetilde{b}_{\gamma}^{+}\right\}\right]$for all $\gamma \in[0,1]$.

If the $\gamma$-cut set $\widetilde{b}_{\gamma}$ does not contain zero $\forall \gamma \in[0,1]$, then $\tilde{a} / \widetilde{b}$ is also a fuzzy number and its $\gamma$-cut set is

$$
\begin{aligned}
& \left(\frac{\tilde{a}}{\tilde{b}}\right)_{\gamma}=\left[\min \left\{\frac{\tilde{a}_{\gamma}^{-}}{\tilde{b}_{\gamma}^{-}}, \frac{\tilde{a}_{\gamma}^{-}}{\tilde{b}_{\gamma}^{+}}, \frac{\tilde{a}_{\gamma}^{+}}{\tilde{b}_{\gamma}^{-}}, \frac{\tilde{a}_{\gamma}^{+}}{\tilde{b}_{\gamma}^{+}}\right\},\right. \\
& \left.\max \left\{\frac{\tilde{a}_{\gamma}^{-}}{\tilde{b}_{\gamma}^{-}}, \frac{\tilde{a}_{\gamma}^{-}}{\tilde{b}_{\gamma}^{+}}, \frac{\tilde{a}_{\gamma}^{+}}{\tilde{b}_{\gamma}^{+}}, \frac{\tilde{a}_{\gamma}^{+}}{\tilde{b}_{\gamma}^{+}}\right\}\right] .
\end{aligned}
$$

In addition, if $\lambda>0$, then we have $(\lambda \widetilde{a})_{\gamma}:=\left[\lambda \widetilde{a}_{\gamma}^{-}, \lambda \widetilde{a}_{\gamma}^{+}\right], \gamma \in$ $[0,1]$.

Proposition 3 (see [31]). Let $f\left(x_{1}, x_{2}, \ldots, x_{n}\right)$ be a realvalued function defined on $R^{n}$ and $\widetilde{a}_{1}, \widetilde{a}_{2}, \ldots, \widetilde{a}_{n}$ are $n$ fuzzy numbers. Let $\tilde{f}: F^{n} \rightarrow F$ be a fuzzy-valued function induced 
by $f\left(x_{1}, \ldots, x_{n}\right)$ via the extension principle. Suppose that each $\left\{\left(x_{1}, \ldots, x_{n}\right): r=f\left(x_{1}, \ldots, x_{n}\right)\right\}$ is a compact subset of $R^{n}$ for $r$ in the range of $f$. Then $\tilde{f}\left(\widetilde{a}_{1}, \tilde{a}_{2}, \ldots, \tilde{a}_{n}\right)$ is a fuzzy number and its $\gamma$-cut set is $\tilde{f}_{\gamma}=\left\{f\left(x_{1}, \ldots, x_{n}\right): x_{1} \in\left(\tilde{a}_{1}\right)_{\gamma}, \ldots, x_{n} \in\right.$ $\left.\left(\widetilde{a}_{n}\right)_{\gamma}\right\}$.

Next, we review the fuzzy random variables, which take values in fuzzy number.

Definition 4 (see [33]). A fuzzy-number-valued map $X$ is called a fuzzy random variable if $\{(\omega, x) \in \Omega \times R \mid X(\omega)(x) \geq$ $\gamma\}$ is measurable for all $\gamma \in[0,1]$. It is called integrably bounded if both $\omega \rightarrow X_{\gamma}^{-}(\omega)$ and $\omega \rightarrow X_{\gamma}^{+}(\omega)$ are integrable for all $\gamma \in[0,1]$.

\section{Main Results}

The total return swap is a special type of credit derivative; the two sides involved in the contract are generally banks and hedge funds. One side of the total return swap will receive the interest plus capital gains or capital losses on the reference credit assets of the contract during the period, and the other side will get the fixed or floating cash flow that is independent of the value of the credit on the credit assets. The credit protection buyer of the contract will transfer all benefits obtained from the reference credit assets to the credit protection seller and get a prior agreement on the rate of return. The rate can be a floating rate or a fixed rate. In other words, the total return swap can not only transfer the credit risk, but can also transfer the interest rate risk and other risks. Thus in total return swap pricing, we need to consider both credit risk and interest rate risk, following the research methods in the literature [34].

In the total return swap agreement, we assume that the credit protection buyer is $A$ and the credit protection seller is $B$. The interest on reference credit assets plus value added will be paid to party $B$ by party $A$ (if the value is negative, then the corresponding minus), and the LIBOR plus agreement spreads will be paid to party $A$ by party $B$ (the spread in this agreement is the so-called total return swap price or fair premium).

LIBOR is the London Interbank Offered Rate, as well as the benchmark interest rate in the international financial market relative to the most floating interest rates, and LIBOR rates are common for 3 months and 6 months. A special LIBOR interest rate model was given in the literature [35] as $L(t, T)=(p(t, T)-p(t, T+\delta)) / \delta p(t, T+\delta)$; they called $L(t, T)$ the forward LIBOR rate, and, when $t=T$, it is $L(t, T)$ as the spot LIBOR rate, and $\delta$ is known as the LIBOR period. $p(t, T)$ is the price of default-free zero coupon bonds at time $t$, whose maturity payment is $\$ 1$.

We assume that the value of reference credit assets at time $t_{0}$ is $V_{0}$, the face value is $F$, and the interests are paid in the discrete point times $0<t_{1}<t_{2}<\cdots<t_{N}=T$, and the reference entity and the total return swap have the same due date $T$. So the party $A$ will pay a total cash flow in the future as follows:

$$
\mathrm{cf}_{A}=\sum_{i=1}^{N} C_{i} \times 1_{\left\{\tau>t_{i}\right\}}+\left(F-V_{0}\right) \times 1_{\left\{\tau>t_{N}\right\}},
$$

where $C_{i}$ is the interest paid by the reference entity at time $t_{i}$, which is known at the time $t_{0}$ and $1_{\left\{\tau>t_{i}\right\}}$ is the default index function; that is, the value of function is 1 when the reference asset default occurred; otherwise the function value is 0 ; $\tau$ is the reference asset default time. Meanwhile, the party $B$ will pay a total cash flow in the future as follows:

$$
\begin{aligned}
\mathrm{cf}_{B}= & \sum_{i=1}^{N}\left(L\left(t_{i-1}, t_{i-1}\right)+s\right) \times \delta \times N V \times 1_{\left\{\tau>t_{i}\right\}} \\
& +\left(1-\delta^{\prime}\right) \times F \times 1_{\left\{\tau \leq t_{N}\right\}},
\end{aligned}
$$

where, $L\left(t_{i-1}, t_{i-1}\right)$ is the LIBOR rate at time $t_{i-1}, s$ is the fair premium for the total return swap, $N V$ is the nominal principal of the total return swap contract, and $\delta^{\prime}$ is the default recovery rate for the reference entities, and they meet $\delta^{\prime} \in[0,1)$.

Under the risk neutral measure, according to the no arbitrage pricing principle, the expectation of the present value of the cash flow paid by the party $A$ and party $B$ shall be equal to

$$
E^{\mathrm{Q}}\left[D\left(t_{i}\right) \mathrm{cf}_{A}\right]=E^{\mathrm{Q}}\left[D\left(t_{i}\right) \mathrm{cf}_{B}\right]
$$

specifically, there are the following equations:

$$
\begin{aligned}
& E^{Q}\left[\sum_{i=1}^{N} D\left(t_{i}\right) \times C_{i} \times 1_{\left\{\tau>t_{i}\right\}}+D\left(t_{N}\right)\left(F-V_{0}\right)\right. \\
& \left.\quad \times 1_{\left\{\tau>t_{N}\right\}}\right]=E^{Q}\left[\sum_{i=1}^{N} D\left(t_{i}\right)\left(L\left(t_{i-1}, t_{i-1}\right)+s\right) \times \delta\right. \\
& \left.\quad \times N V \times 1_{\left\{\tau>t_{i}\right\}}+D(\tau)\left(1-\delta^{\prime}\right) \times F \times 1_{\left\{\tau \leq t_{N}\right\}}\right]
\end{aligned}
$$

thus, the calculation formula of the fair premium of the total return swap can be obtained as follows:

$$
\begin{aligned}
s= & \frac{E^{\mathrm{Q}}\left[\sum_{i=1}^{N} D\left(t_{i}\right) \times C_{i} \times 1_{\left\{\tau>t_{i}\right\}}\right]+E^{\mathrm{Q}}\left[D\left(t_{N}\right)\left(F-V_{0}\right) \times 1_{\left\{\tau>t_{N}\right\}}\right]}{E^{\mathrm{Q}}\left[\sum_{i=1}^{N} D\left(t_{i}\right) \times \delta \times N V \times 1_{\left\{\tau>t_{i}\right\}}\right]} \\
& -\frac{E^{\mathrm{Q}}\left[\sum_{i=1}^{N} D\left(t_{i}\right) L\left(t_{i-1}, t_{i-1}\right) \times \delta \times N V \times 1_{\left\{\tau>t_{i}\right\}}\right]+E^{\mathrm{Q}}\left[D(\tau)\left(1-\delta^{\prime}\right) \times F \times 1_{\left\{\tau \leq t_{N}\right\}}\right]}{E^{\mathrm{Q}}\left[\sum_{i=1}^{N} D\left(t_{i}\right) \times \delta \times N V \times 1_{\left\{\tau>t_{i}\right\}}\right]},
\end{aligned}
$$


where $E^{\mathrm{Q}}$ represents the expected value of the risk neutral measure and $D\left(t_{i}\right)$ is the account process or discount factor. Obviously, the key to solving formula (7) lies in the calculation of the probability of default and the description of interest rate risk.

3.1. Default Distribution in a Fuzzy Random Environment. In this paper, the default time of reference entity is calculated by the first-arrival model of the structure model, because it has a strong explanatory power to the reality of the event of default. The structural model was first proposed in the literature [36] where the author considered the default event an endogenous variable related to the company's asset value. At the time, he used the company's asset value and liability information to establish a default model. In this paper, we assume that the reference asset value $V(t)$ follows the geometry Lévy process, $V_{t}=V_{0} e^{X_{t}}, V_{0}>0$, where, $X_{t}$ represents the Lévy process; according to the formula of the Lévy-Khintchine, we know that the Lévy process can be decomposed into a possible infinite accumulation of Brownian motion and independent Poisson processes with drift, so we can assume that $X_{t}=$ $\mu t+\sigma W_{t}+\sum_{i=1}^{N(t)} Y_{i}$, where, $N(t)$ is a Poisson process with a strength parameter of $\lambda>0, W_{t}$ stands for the standard Brownian movement for the Wiener process defining the asset value, and $\left\{Y_{i}\right\}$ represent a sequence of independent and identically distributed nonnegative random variables, which are used to describe the jump size of the asset value; the density function is an asymmetric double exponential distribution, $f(y)=p \eta_{1} e^{-\eta_{1} y} 1_{\{y \geq 0\}}+q \eta_{2} e^{\eta_{2} y} 1_{\{y<0\}}, \eta_{1}>$ $1, \eta_{2}>0$, where $p$ represents the probability of jumping up, $q$ represents the probability of jumping down, and $p+$ $q=1$ and $1 / \eta_{1}, 1 / \eta_{2}$ stand for the mean jump size, and all stochastic processes $N(t), W_{t}$, and $\left\{Y_{i}\right\}$ are independent of each other; that is, the asset value $V(t)$ follows the double exponential jump diffusion process (the risk neutral measure under the jump diffusion model is not unique, and it depends on the consumer's utility function). The double exponential distribution has a unique advantage in the characterization of the jumping behavior of financial assets: First, it allows a jump up and down on both sides of the asset fluctuation, and the jump size can be nonsymmetric; this provides the possibility of describing the characteristics of the higher peak and fat tail phenomenon of the real financial data. Second, the double exponential distribution has the characteristic of having no memory, which makes it easy to calculate expectations and variances.

In order to obtain the distribution function of the time of the reference entity, first of all, we need to calculate the moment generating function of the asset value jump variables $\left\{Y_{i}\right\}$. Under the condition of crisp number, we assume that $\theta \in\left(-\eta_{2}, \eta_{1}\right)$; then the moment generating function of the jump variables $\left\{Y_{i}\right\}$ is $E^{Q}\left[e^{\theta Y_{t}}\right]=e^{G(\theta) t}$, where $G(\theta)=\mu \theta+$ $(1 / 2) \sigma^{2} \theta+\lambda\left(p \eta_{1} /\left(\eta_{1}-\theta\right)+q \eta_{2} /\left(\eta_{2}+\theta\right)-1\right)$ represents the Laplace Exponent of the Lévy process. The solution of the Laplace exponent equation $G(\theta)$ is given in the following lemma (this lemma is used to the Laplace conversion for the default time).
Lemma 5 (see [37]). For arbitrary positive real number $\alpha>0$, equation $G(\theta)=\alpha$ has and only has four real roots $\beta_{1, \alpha}<$ $\beta_{2, \alpha}<-\beta_{3, \alpha}<-\beta_{4, \alpha}$, and they meet the following conditions: $-\infty<-\beta_{4, \alpha}<-\eta_{2}<-\beta_{3, \alpha}, 0<\beta_{1, \alpha}<\eta_{1}<\beta_{2, \alpha}<\infty$.

As mentioned above, under the condition of the market having a variety of uncertain factors, the factors affecting the pricing of financial products are not only randomness, but also fuzziness. In order to highlight the influence of fuzziness in the process of asset value jumping on the pricing of derivatives, in this paper, we assume that the representation of the characterization of the jump intensity $\widetilde{\lambda}$ and jump amplitude $\tilde{\eta}_{1}, \widetilde{\eta}_{2}$ of asset value are triangular fuzzy numbers.

$$
\begin{aligned}
& a_{0}=\lambda d_{0}^{-}, \\
& b_{0}=\lambda d_{0}^{+}, \\
& a_{1}=\eta_{1} d_{1}^{-}, \\
& b_{1}=\eta_{1} d_{1}^{+}, \\
& a_{2}=\eta_{2} d_{2}^{-}, \\
& b_{2}=\eta_{2} d_{2}^{+},
\end{aligned}
$$$$
\tilde{\lambda}_{\gamma}=\left[\lambda-(1-\gamma) a_{0}, \lambda+(1-\gamma) b_{0}\right],
$$$$
\tilde{\eta}_{1, \gamma}=\left[\eta_{1}-(1-\gamma) a_{1}, \eta_{1}+(1-\gamma) b_{1}\right] \text {, }
$$$$
\tilde{\eta}_{2, \gamma}=\left[\eta_{2}-(1-\gamma) a_{2}, \eta_{2}+(1-\gamma) b_{2}\right] \text {, }
$$$$
\gamma \in[0,1], \lambda>0, \eta_{1}>1, \eta_{2}>0,
$$

$$
0<d_{0}^{-}, d_{1}^{-}, d_{2}^{-}, d_{0}^{+}, d_{1}^{+}, d_{2}^{+}<1,
$$

where $\gamma$ stands for the subjective judgment reliability on fuzzy information in the financial market (a restriction is needed on the values of $\gamma$ in order to avoid negativity and allow for an interpretation as jump intensity and amplitude; for example, we can assume that $\gamma \in[0,1])$. As a result, if we assume $\beta_{1, \alpha}, \beta_{2, \alpha}$ are the only two positive real root of $G(\theta)=\alpha$, then, based on the literature $[30,37]$, we can derived the $\gamma$-cut set of the positive real root of the equation $G(\theta)=\alpha$ under the fuzzy random environment.

$$
\begin{aligned}
\tilde{\beta}_{1, \alpha, \gamma} & =\left[\beta_{1, \alpha}-(1-\gamma) a_{3}, \beta_{1, \alpha}+(1-\gamma) b_{3}\right], \\
\tilde{\beta}_{2, \alpha, \gamma} & =\left[\beta_{2, \alpha}-(1-\gamma) a_{4}, \beta_{2, \alpha}+(1-\gamma) b_{4}\right], \\
a_{3} & =\beta_{1 \alpha} d_{3}^{-}, \\
b_{3} & =\beta_{1 \alpha} d_{3}^{+}, \\
a_{4} & =\beta_{2 \alpha} d_{4}^{-}, \\
b_{4} & =\beta_{2 \alpha} d_{4}^{+},
\end{aligned}
$$

$$
0<d_{3}^{-}, d_{4}^{-}, d_{3}^{+}, d_{4}^{+}<1
$$


When the reference value is lower than the default threshold $K$ (where $K$ is determined by exogenous factors and assumed to be constant), then the default event will happen, so that the default time is defined as $\tau=\inf \left\{t \geq 0, V_{t} \leq\right.$ $K\}=\inf \left\{t \geq 0, X_{t} \leq K^{*}\right\}, K^{*}=\log K / V_{0}<0$; therefore, the distribution function of the reference entity default time is

$$
F(t)=F(\tau \leq t)=F\left(\inf _{0 \leq s \leq t} X_{s} \leq K^{*}\right)
$$

then the default time has the following Laplace conversion formula under the fuzzy random environment: $E^{\mathrm{Q}}\left(e^{-\alpha \tau}\right)=$ $\left(\left(\widetilde{\eta}_{1}-\widetilde{\beta}_{1, \alpha}\right) / \widetilde{\eta}_{1}\right)\left(\widetilde{\beta}_{2, \alpha} /\left(\widetilde{\beta}_{2, \alpha}-\widetilde{\beta}_{1, \alpha}\right)\right) e^{-K^{*} \tilde{\beta}_{1, \alpha}}+\left(\left(\widetilde{\beta}_{2, \alpha}-\widetilde{\eta}_{1}\right) /\right.$ $\left.\tilde{\eta}_{1}\right)\left(\widetilde{\beta}_{1, \alpha} /\left(\widetilde{\beta}_{2, \alpha}-\widetilde{\beta}_{1, \alpha}\right)\right) e^{-K^{*} \widetilde{\beta}_{2, \alpha}}$. At the same time, the distribution function of default time can be derived by the definition of Laplace Transformation, $\widehat{F}(\alpha)=\int_{0}^{\infty} e^{-\alpha t} F(\tau \leq t) d t=(1 /$

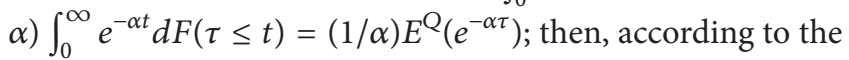
Laplace Gaver-Stehfest inversion algorithm, we can get the analytic expression of the default time distribution function $F(t)=F(\tau \leq t)=\lim _{n \rightarrow \infty} \widehat{F}_{n}(t)$, where

$$
\begin{aligned}
& \widehat{F}_{n}(t) \\
& \quad=\frac{\log 2}{t} \frac{(2 n) !}{n !(n-1) !} \sum_{k=0}^{n}(-1)^{k}\left(\begin{array}{l}
n \\
k
\end{array}\right) \widehat{F}\left((n+k) \frac{\log 2}{t}\right) .
\end{aligned}
$$

In order to accelerate the convergence, a linear sum approximation is given. In the fifth section of the literature [37], the authors point out that, in the Gaver-Stehfest algorithm, if $n=1,2$ terms are omitted in the formula $\widehat{F}_{n}(t)$, the stability of numerical calculation can be increased; that is, when $n$ is large enough we have $F(t) \approx \sum_{k=1}^{n}(-1)^{n-k}\left(k^{n} / k !(n-k) !\right) \widehat{F}_{k+2}(t)$; at the same time, we have $\sum_{k=1}^{n}(-1)^{n-k}\left(k^{n} / k !(n-k) !\right) \widehat{F}_{k+2}(t)-$ $F(t)=o\left(n^{-k}\right), n \rightarrow \infty$. And when the $n$ value is between 5 and 10 , the algorithm can quickly converge. Finally, the $\gamma$-cut set of the triangular fuzzy number of the default distribution of the reference asset value is obtained in the fuzzy random environment.

$$
\begin{aligned}
\widetilde{F}_{\gamma}(t)=\left[F(t)-(1-\gamma) a_{5}, F(t)+(1-\gamma) b_{5}\right] & \\
\gamma & \in[0,1] .
\end{aligned}
$$

3.2. Interest Rate Risk in Fuzzy Random Environment. For the description of interest rate risk, this paper follows the CIR (Cox-Ingersoll-Ross) model; that is, $d r_{t}=\alpha^{\prime}\left(k^{\prime}-\right.$ $\left.r_{t}\right) d t+\sigma^{\prime} \sqrt{r_{t}} d \widetilde{W}_{t}$, where $\alpha^{\prime}$ represents the rate of return, $k^{\prime}$ represents the long-term average level, $\sigma^{\prime}$ stands for the fluctuation of interest rate, and $\widetilde{W}_{t}$ stands for the standard Brownian movement for the Wiener process defining the interest rate. Then the price of default-free zero coupon bond is $p(t, T)=E^{\mathrm{Q}}[D(t)]=E^{\mathrm{Q}}\left[\exp \left(-\int_{t}^{T} r_{s} d s\right)\right]$.

According to the conclusion of [38], we have $p(t, T)=$ $e^{-r_{t} C(t, T)-A(t, T)}$, where

$C(t, T)$

$$
\begin{aligned}
& =\frac{e^{\rho(T-t)}-e^{-\rho(T-t)}}{\left(\rho+(1 / 2) \alpha^{\prime}\right) e^{\rho(T-t)}+\left(\rho-(1 / 2) \alpha^{\prime}\right) e^{-\rho(T-t)}}, \\
& A(t, T)=-\alpha^{\prime} k^{\prime} \int_{t}^{T} C(s, T) d s, \\
& \rho=\frac{1}{2} \sqrt{\alpha^{\prime 2}+2 \sigma^{\prime 2}}
\end{aligned}
$$

As, due to unforeseen circumstances or man-made flaws, financial data may not be timely or records not accurate, interest rates in different banks or financial institutions may not be the same. Although the differences may be minute, it is not reasonable to assume that they are constant. In order to reflect the influence of fuzziness on interest rates, this paper also assumes that the market short-term interest rates are triangular fuzzy numbers.

$$
\begin{aligned}
\widetilde{r}(t)=\left[r(t)-(1-\gamma) a_{6}, r(t)+(1-\gamma) b_{6}\right], & \\
& \gamma \in[0,1] .
\end{aligned}
$$

Theorem 6. Suppose that the market short-term interest rate $\tilde{r}(t)$ satisfies the CIR model, then the $\gamma$-cut of the price of default-free zero coupon bond, whose face value is $\$ 1$ and expiration date is $T$, can be written as $\widetilde{p}_{\gamma}(t, T)=\left[\tilde{p}_{\gamma}^{-}, \tilde{p}_{\gamma}^{+}\right]$, where the left and right ends, respectively, are

$$
\begin{aligned}
& \widetilde{p}_{\gamma}^{-}(t, T)=e^{-\left(1+(1-\gamma) c^{+}\right) r C(t, T)-A(t, T)}, \\
& \widetilde{p}_{\gamma}^{+}(t, T)=e^{-\left(1-(1-\gamma) c^{-}\right) r C(t, T)-A(t, T)}, \\
& \gamma \in[0,1] .
\end{aligned}
$$

Proof. Based on the monotonicity of the function and Proposition 2, we can come to the conclusion.

3.3. The Total Return Swap Pricing Model with Fuzzy Analysis. Because the first-arrival model is used in this paper to describe the default time of reference, and as it is assumed that the default time and the interest rate process are independent of each other, we can derive the following triangular fuzzy form of the total return swap pricing formula.

Theorem 7. The $\gamma$-cut set left end point of triangular fuzzy form of TRS pricing formula is

$$
\begin{aligned}
\widetilde{s}_{\gamma}= & \frac{C_{i} \times \sum_{i=1}^{N} e^{-\left(1+(1-\gamma) c^{+}\right) r C\left(t_{i}, T\right)-A\left(t_{i}, T\right)} \times\left(1-\left(1+(1-\gamma) d^{+}\right) F\left(t_{i}\right)\right)}{\delta \times N V \times \sum_{i=1}^{N} e^{-\left(1-(1-\gamma) c^{-}\right) r C\left(t_{i}, T\right)-A\left(t_{i}, T\right)} \times\left(1-\left(1-(1-\gamma) d^{-}\right) F\left(t_{i}\right)\right)} \\
& +\frac{\left(F-V_{0}\right) \times\left(1-\left(1+(1-\gamma) d^{+}\right) F\left(t_{N}\right)\right)}{\delta \times N V \times \sum_{i=1}^{N} e^{-\left(1-(1-\gamma) c^{-}\right) r C\left(t_{i}, T\right)-A\left(t_{i}, T\right)} \times\left(1-\left(1-(1-\gamma) d^{-}\right) F\left(t_{i}\right)\right)}
\end{aligned}
$$




$$
\begin{aligned}
& -\frac{L\left(t_{i-1}, t_{i-1}\right) \times \delta \times N V \times \sum_{i=1}^{N} e^{-\left(1-(1-\gamma) c^{-}\right) r C\left(t_{i}, T\right)-A\left(t_{i}, T\right)} \times\left(1-\left(1-(1-\gamma) d^{-}\right) F\left(t_{i}\right)\right)}{\delta \times N V \times \sum_{i=1}^{N} e^{-\left(1-(1-\gamma) c^{-}\right) r C\left(t_{i}, T\right)-A\left(t_{i}, T\right)} \times\left(1-\left(1-(1-\gamma) d^{-}\right) F\left(t_{i}\right)\right)} \\
& -\frac{\left(1-\delta^{\prime}\right) \times F \times e^{-\left(1-(1-\gamma) c^{-}\right) r C(\tau, T)-A(\tau, T)} \times\left(1+(1-\gamma) d^{+}\right) F\left(t_{N}\right)}{\delta \times N V \times \sum_{i=1}^{N} e^{-\left(1-(1-\gamma) c^{-}\right) r C\left(t_{i}, T\right)-A\left(t_{i}, T\right)} \times\left(1-\left(1-(1-\gamma) d^{-}\right) F\left(t_{i}\right)\right)} .
\end{aligned}
$$

Proof. In the fuzzy random environment, according to formula (7) and the properties of expectation $\left(E^{Q}\right.$ can be abbreviated as $E$ ), we have the following conclusions:

$$
\begin{aligned}
E\left[\sum_{i=1}^{N} D\left(t_{i}\right) \times \delta \times N V \times 1_{\left\{\tau>t_{i}\right\}}\right]_{\gamma}^{+} \\
=\delta \times N V \times \sum_{i=1}^{N} e^{-\left(1-(1-\gamma) c^{-}\right) r C\left(t_{i}, T\right)-A\left(t_{i}, T\right)} \\
\quad \times\left(1-\left(1-(1-\gamma) d^{-}\right) F\left(t_{i}\right)\right), \\
E\left[\sum_{i=1}^{N} D\left(t_{i}\right) \times C_{i} \times 1_{\left\{\tau>t_{i}\right\}}\right]_{\gamma}^{-} \\
=C_{i} \times \sum_{i=1}^{N} e^{-\left(1+(1-\gamma) c^{+}\right) r C\left(t_{i}, T\right)-A\left(t_{i}, T\right)} \\
\quad \times\left(1-\left(1+(1-\gamma) d^{+}\right) F\left(t_{i}\right)\right), \\
E\left[D\left(t_{N}\right)\left(F-V_{0}\right) \times 1_{\left\{\tau>t_{N}\right\}}\right]_{\gamma}^{-} \\
=\left(F-V_{0}\right) \times e^{-\left(1+(1-\gamma) c^{+}\right) r C(T, T)-A(T, T)} \\
\quad \times\left(1-\left(1+(1-\gamma) d^{+}\right) F\left(t_{N}\right)\right),
\end{aligned}
$$

$$
\begin{aligned}
& E\left[\sum_{i=1}^{N} D\left(t_{i}\right) L\left(t_{i-1}, t_{i-1}\right) \times \delta \times N V \times 1_{\left\{\tau>t_{i}\right\}}\right]_{\gamma}^{+} \\
& =L\left(t_{i-1}, t_{i-1}\right) \times \delta \times N V \\
& \quad \times \sum_{i=1}^{N} e^{-\left(1-(1-\gamma) c^{-}\right) r C\left(t_{i}, T\right)-A\left(t_{i}, T\right)} \\
& \quad \times\left(1-\left(1-(1-\gamma) d^{-}\right) F\left(t_{i}\right)\right), \\
& E\left[D(\tau)\left(1-\delta^{\prime}\right) \times F \times 1_{\left\{\tau \leq t_{N}\right\}}\right]_{\gamma}^{+} \\
& =\left(1-\delta^{\prime}\right) \times F \times e^{-\left(1-(1-\gamma) c^{-}\right) r C(\tau, T)-A(\tau, T)} \\
& \quad \times\left(1+(1-\gamma) d^{+}\right) F\left(t_{N}\right) .
\end{aligned}
$$

Bring the result of the above expectation into formula (7) and according to the monotonic property of the function, we can come to the conclusion.

Theorem 8. The $\gamma$-cut set right end point of triangular fuzzy form of the total return swap pricing formula is

$$
\begin{aligned}
\widetilde{s}_{\gamma}^{+}= & \frac{C_{i} \times \sum_{i=1}^{N} e^{-\left(1-(1-\gamma) c^{-}\right) r C\left(t_{i}, T\right)-A\left(t_{i}, T\right)} \times\left(1-\left(1-(1-\gamma) d^{-}\right) F\left(t_{i}\right)\right)}{\delta \times N V \times \sum_{i=1}^{N} e^{-\left(1+(1-\gamma) c^{+}\right) r C\left(t_{i}, T\right)-A\left(t_{i}, T\right)} \times\left(1-\left(1+(1-\gamma) d^{+}\right) F\left(t_{i}\right)\right)} \\
& +\frac{\left(F-V_{0}\right) \times\left(1-\left(1-(1-\gamma) d^{-}\right) F\left(t_{N}\right)\right)}{\delta \times N V \times \sum_{i=1}^{N} e^{-\left(1+(1-\gamma) c^{+}\right) r C\left(t_{i}, T\right)-A\left(t_{i}, T\right)} \times\left(1-\left(1+(1-\gamma) d^{+}\right) F\left(t_{i}\right)\right)} \\
& -\frac{L\left(t_{i-1}, t_{i-1}\right) \times \delta \times N V \times \sum_{i=1}^{N} e^{-\left(1+(1-\gamma) c^{+}\right) r C\left(t_{i}, T\right)-A\left(t_{i}, T\right)} \times\left(1-\left(1+(1-\gamma) d^{+}\right) F\left(t_{i}\right)\right)}{\delta \times N V \times \sum_{i=1}^{N} e^{-\left(1+(1-\gamma) c^{+}\right) r C\left(t_{i}, T\right)-A\left(t_{i}, T\right)} \times\left(1-\left(1+(1-\gamma) d^{+}\right) F\left(t_{i}\right)\right)} \\
& -\frac{\left(1-\delta^{\prime}\right) \times F \times e^{-\left(1+(1-\gamma) c^{+}\right) r C(\tau, T)-A(\tau, T)} \times\left(1-(1-\gamma) d^{-}\right) F\left(t_{N}\right)}{\delta \times N V \times \sum_{i=1}^{N} e^{-\left(1+(1-\gamma) c^{+}\right) r C\left(t_{i}, T\right)-A\left(t_{i}, T\right)} \times\left(1-\left(1+(1-\gamma) d^{+}\right) F\left(t_{i}\right)\right)} .
\end{aligned}
$$

Proof. In the fuzzy random environment, according to formula (7) and the properties of expectation $\left(E^{Q}\right.$ can be abbreviated as $E$ ), we have the following conclusions:

$$
E\left[\sum_{i=1}^{N} D\left(t_{i}\right) \times \delta \times N V \times 1_{\left\{\tau>t_{i}\right\}}\right]_{\gamma}^{-}
$$

$$
\begin{gathered}
=\delta \times N V \times \sum_{i=1}^{N} e^{-\left(1+(1-\gamma) c^{+}\right) r C\left(t_{i}, T\right)-A\left(t_{i}, T\right)} \\
\times\left(1-\left(1+(1-\gamma) d^{+}\right) F\left(t_{i}\right)\right) \\
E\left[\sum_{i=1}^{N} D\left(t_{i}\right) \times C_{i} \times 1_{\left\{\tau>t_{i}\right\}}\right]_{\gamma}^{+}
\end{gathered}
$$


TABLE 1: Parameter configuration.

\begin{tabular}{|c|c|c|}
\hline Parameter classification & Parameter name & Parameter hypothesis and configuration \\
\hline \multirow{2}{*}{ Time parameter } & Expiration date $T$ & $\begin{array}{c}\text { At present, the largest trading volume of TRS contract is } 5 \text { years; } \\
\text { therefore, hypothesize that } T=5\end{array}$ \\
\hline & $\begin{array}{l}\text { Premium payment } \\
\text { date } t_{i}\end{array}$ & $\begin{array}{l}\text { According to international practice, the premium payment cycle is } \\
\text { usually a quarter; that is, } \Delta t_{i}=0.25\end{array}$ \\
\hline \multirow[t]{2}{*}{ Discount parameter } & LIBOR & $\begin{array}{l}\text { The benchmark interest rate in the international financial market is } \\
\text { London Interbank Offered Rate and usually is } 0.5 \text { or } 1\end{array}$ \\
\hline & $\begin{array}{l}\text { Risk-free interest rate } \\
r\end{array}$ & $r$ use period counting rates or yields \\
\hline \multirow{2}{*}{ Default parameter } & $\begin{array}{l}\text { Default recovery rate } \\
\delta^{\prime}\end{array}$ & $\begin{array}{l}\text { Reference to international common assumptions, suppose that } \\
\qquad \delta^{\prime}=0.5\end{array}$ \\
\hline & Default threshold $K$ & $\begin{array}{l}\text { The default threshold selection can be divided into endogenous and } \\
\text { exogenous; we assume that } K \text { is a constant and decided by exogenous }\end{array}$ \\
\hline
\end{tabular}

credit spreads unit in base points).

$$
\begin{aligned}
= & C_{i} \times \sum_{i=1}^{N} e^{-\left(1-(1-\gamma) c^{-}\right) r C\left(t_{i}, T\right)-A\left(t_{i}, T\right)} \\
& \times\left(1-\left(1-(1-\gamma) d^{-}\right) F\left(t_{i}\right)\right), \\
E[ & \left.D\left(t_{N}\right)\left(F-V_{0}\right) \times 1_{\left\{\tau>t_{N}\right\}}\right]_{\gamma}^{+} \\
= & \left(F-V_{0}\right) \times e^{-\left(1-(1-\gamma) c^{-}\right) r C(T, T)-A(T, T)} \\
& \times\left(1-\left(1-(1-\gamma) d^{-}\right) F\left(t_{N}\right)\right), \\
E\left[\sum_{i=1}^{N}\right. & \left.D\left(t_{i}\right) L\left(t_{i-1}, t_{i-1}\right) \times \delta \times N V \times 1_{\left\{\tau>t_{i}\right\}}\right]_{\gamma}^{-} \\
= & L\left(t_{i-1}, t_{i-1}\right) \times \delta \times N V \\
& \times \sum_{i=1}^{N} e^{-\left(1+(1-\gamma) c^{+}\right) r C\left(t_{i}, T\right)-A\left(t_{i}, T\right)} \\
& \times\left(1-\left(1+(1-\gamma) d^{+}\right) F\left(t_{i}\right)\right), \\
E[ & \left.D(\tau)\left(1-\delta^{\prime}\right) \times F \times 1_{\left\{\tau \leq t_{N}\right\}}\right]_{\gamma}^{-} \\
= & \left(1-\delta^{\prime}\right) \times F \times e^{-\left(1+(1-\gamma) c^{+}\right) r C(\tau, T)-A(\tau, T)} \\
& \times\left(1-(1-\gamma) d^{-}\right) F\left(t_{N}\right) .
\end{aligned}
$$

Again bring the result of the above expectation into formula (7) and according to the monotonic property of the function, we can come to the conclusion.

In this way, we get the $\gamma$-cut set $\widetilde{s}_{\gamma}=\left[\widetilde{s}_{\gamma}, \widetilde{s}_{\gamma}^{+}\right]$of the fair premium of the total return swap of triangular fuzzy forms.

Note 1. In Theorems 7 and $8, F(t) \approx \sum_{k=1}^{n}(-1)^{n-k}\left(k^{n} / k !(n-\right.$ k)!) $\widehat{F}_{k+2}(t)$.
Note 2. In order to simplify the discussion, inspired by the literature [4], we give a reasonable hypothesis: the divergence factor $a_{5}, b_{5}$ can be assumed to be $a_{5}=d^{-} F(t), b_{5}=$ $d^{+} F(t)$, where $0<d^{-}, d^{+}<1$ (So $d^{-}, d^{+}$will correspond with $a_{5}, b_{5}$, which will be able to characterize the degree of fuzziness of information). The assumption is feasible because the divergence factor $a_{5}, b_{5}$ is associated with the fuzziness of the volatility of financial markets. Therefore there are the following results: $\widetilde{F}_{\gamma}(t)=\left[\left(1-(1-\gamma) d^{-}\right) F(t),(1+(1-\right.$ $\left.\left.\gamma) d^{+}\right) F(t)\right]$.

Similar to above, we have $\widetilde{r}(t)=\left[\left(1-(1-\gamma) c^{-}\right) r(t),(1+\right.$ $\left.\left.(1-\gamma) c^{+}\right) r(t)\right], \gamma \in[0,1]$.

In the uncertain economic system with both fuzziness and randomness, the fair premium of the total return swap is represented as a fuzzy interval, in order to facilitate financial participants for decision making, we can use the defuzzification method to remove the fuzziness; the relevant literature can be found in [39-42].

Inference 1. In the fuzzy random environment, the probability mean of the fair premium of the total return swap with fuzzy analysis obtained by the no arbitrage pricing principle is

$$
M(\widetilde{s})=\int_{0}^{1} f(\gamma)\left(\frac{\widetilde{s_{\gamma}}+\widetilde{s}_{\gamma}^{+}}{2}\right) d \gamma .
$$

\section{Model Simulation Analysis}

In this section, we first simulate the default probability of the double exponential jump diffusion process in a random environment (no fuzziness, that is, the reliability index $\gamma=1$ ); then we give the simulation performance of Theorems 7 and 8 ; that is, the simulation performance of the left and right ends of the fuzzy form of the total return swap fair premium $\gamma$-cut set is given. More specifically, both the influence of the fuzzy degree of market information and the investor's subjective judgment reliability on the premium section of the total return swap are investigated. The parameters involved in the simulation process are in Table 1. 


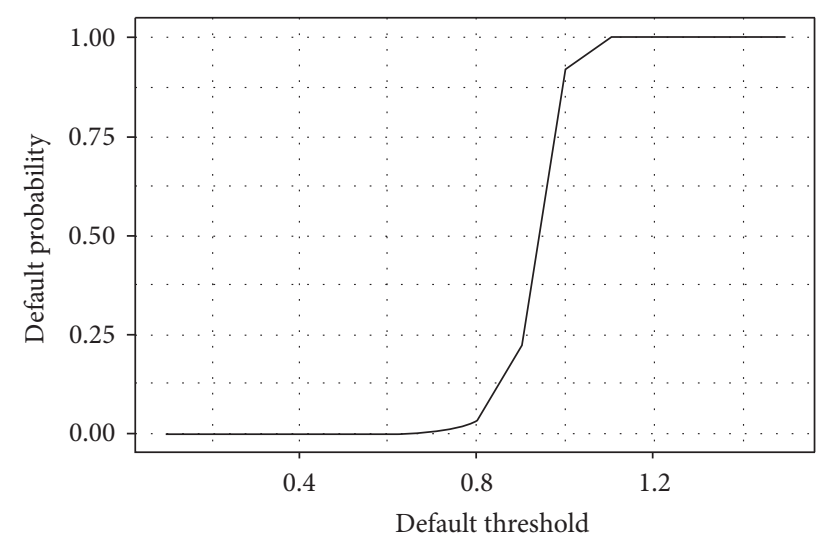

FIGURE 1: Default probability of double exponential jump diffusion process $(K=0.8, \gamma=1)$.

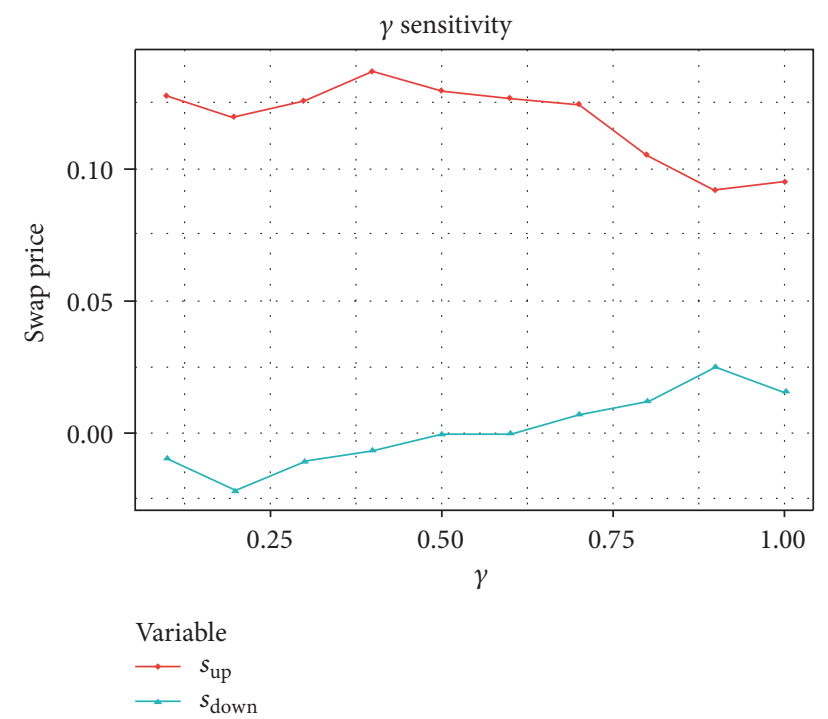

FIGURE 2: Sensitivity analysis of investors' subjective reliability to premium $\left(c^{+}=d^{+}=0.5, c^{-}=d^{-}=0.1, T=1\right)$.

Figure 1 shows that once the asset value has touched the default threshold, the probability of default will increase sharply, which reflects the impact of asset value jump diffusion on corporate default. Figure 2 shows that when the duration of the total return swap contract and the degree of fuzziness of market information are fixed, the length of the total return swap fair premium $\gamma$-cut set is gradually shortened with an increase in the investor's subjective judgment reliability (the value of $\gamma$ represents the personal reliability); that is, the lower and upper bounds are gradually closer. Figures 3(a) and 3(b) show that when the duration of the total return swap contract and the reliability index are fixed, the triangular fuzzy form price range will increase with the degree of fuzziness of information. Figure 4 shows that when the degree of fuzziness of market information and the reliability index are fixed, the triangular fuzzy form price range will increase rapidly with an increase in the contract period (a price cap change is more significant, because we set a larger fuzziness for the price upper bound). This simulation

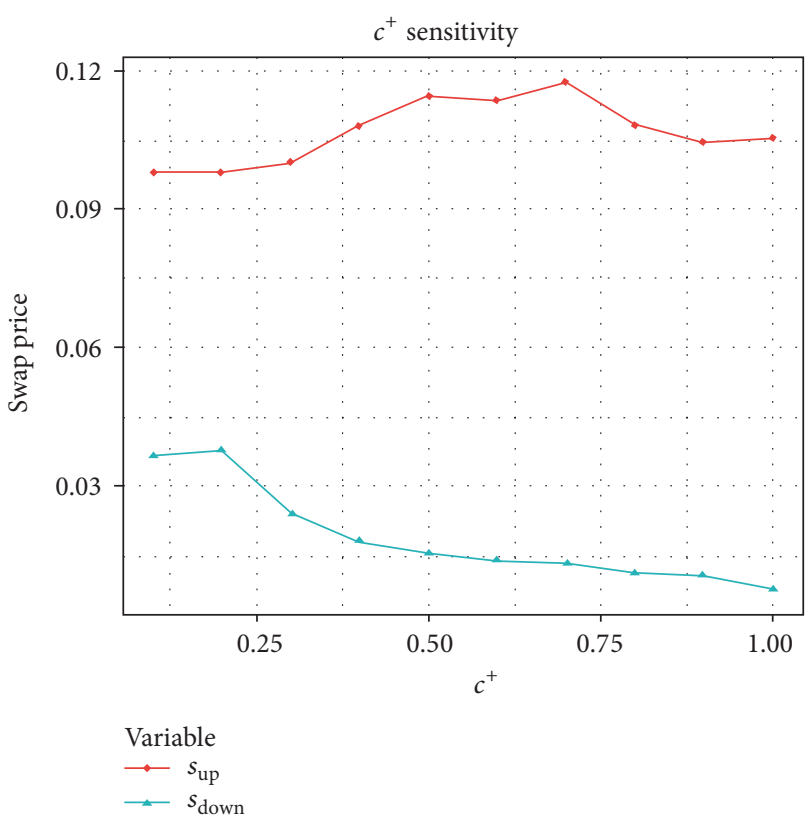

(a)

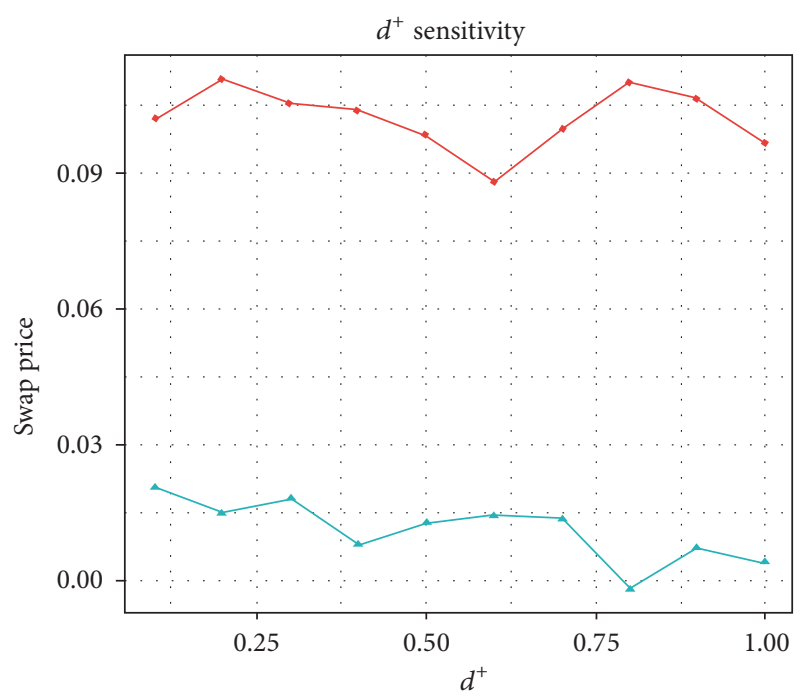

Variable
$\rightarrow-s_{\text {up }}$
$\simeq s_{\text {down }}$

(b)

FIGURE 3: Sensitivity analysis of the degree of fuzzy information on premium $(\gamma=0.8, T=1)$.

shows that both degree of fuzziness in market information and subjective judgment reliability have significant impacts on price changes in the total return swap. The swap price range is proportional to the fuzziness of information and is inversely proportional to subjective judgment reliability. When the duration of the contract becomes longer, market uncertainty will be significantly enhanced with a consequent rapid widening of the price range of the contract. When compared to related literature $[34,43]$, our new fuzzy form TRS pricing model can consider more factors influencing 


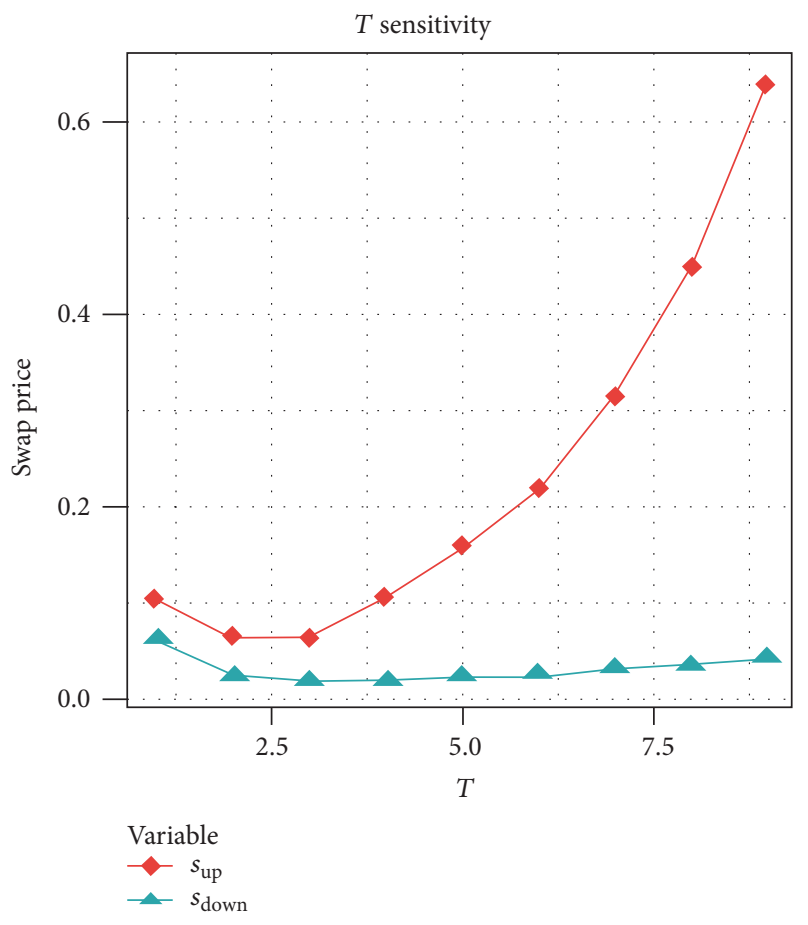

FIGURE 4: Sensitivity analysis of contract period to premium $(\gamma=$ $0.8, c^{+}=d^{+}=0.5, c^{-}=d^{-}=0.1$.

default, is closer to the real complexity of the dynamics of default, can employ the membership function to describe the fuzzy phenomenon, and enables the fuzzy phenomenon to be estimated in two kinds of states: the possible degree and impossible degree and a state that can simultaneously reflect the fuzziness and the randomness of financial markets.

\section{Conclusion}

This paper is based on the fuzziness of information that characterizes real financial markets; it then derives a fuzzy pricing formula for total return swaps using the double exponential jump diffusion model. The conclusion is obtained by simulation. By reducing the fuzziness in market information and by improving the investor's subjective judgment reliability, a more efficient pricing for the total return swap in a fuzzy random environment is revealed. The advantage of this model lies in using both random analysis and fuzzy numbers to identify more uncertain sources in the process of the jump diffusion of asset values and the subjective judgment of investors in the financial markets so as to broaden the scope of possible credit spreads. The proposed model can thus be used as a new tool for TRS pricing. Of course, there are some deficiencies in this paper. Due to limited market data, we did not check the model parameters against market data, and this will be a focus of our future research. Meanwhile, controlling for robustness of model results, that is, the stability of the model results, is also a goal of further research.

\section{Competing Interests}

The authors declare that they have no competing interests.

\section{Acknowledgments}

The work were supported by the general project of Humanities and Social Sciences Research of Henan Provincial Department of Education in 2017 (no. 2017-ZZJH-180) and the Key Research Projects of Henan Provincial Department of Education in 2017 (no. 17A630019).

\section{References}

[1] J. J. Buckley, "The fuzzy mathematics of finance," Fuzzy Sets and Systems, vol. 21, no. 3, pp. 257-273, 1987.

[2] C. Carlsson and R. Fullér, On Fuzzy Real Option Valuation, Turku Centre for Computer Science, 2000.

[3] S. Muzzioli and C. Torricelli, "A model for pricing an option with a fuzzy payoff," Fuzzy Economic Review, vol. 6, no. 1, pp. 49-87, 2001.

[4] Y. Yoshida, "The valuation of European options in uncertain environment," European Journal of Operational Research, vol. 145, no. 1, pp. 221-229, 2003.

[5] Y. Yoshida, M. Yasuda, J.-I. Nakagami, and M. Kurano, "A new evaluation of mean value for fuzzy numbers and its application to American put option under uncertainty," Fuzzy Sets and Systems, vol. 157, no. 19, pp. 2614-2626, 2006.

[6] H.-C. Wu, "Using fuzzy sets theory and Black-Scholes formula to generate pricing boundaries of European options," Applied Mathematics and Computation, vol. 185, no. 1, pp. 136-146, 2007.

[7] W. Xu, C. Wu, W. Xu, and H. Li, "A jump-diffusion model for option pricing under fuzzy environments," Insurance: Mathematics \& Economics, vol. 44, no. 3, pp. 337-344, 2009.

[8] P. Nowak and M. Romaniuk, "Computing option price for Levy process with fuzzy parameters," European Journal of Operational Research, vol. 201, no. 1, pp. 206-210, 2010.

[9] Z. Zmeškal, "Application of the fuzzy-stochastic methodology to appraising the firm value as a European call option," European Journal of Operational Research, vol. 135, no. 2, pp. 303-310, 2001.

[10] M. R. Simonelli, "Fuzziness in valuing financial instruments by certainty equivalents," European Journal of Operational Research, vol. 135, no. 2, pp. 296-302, 2001.

[11] H.-C. Wu, "European option pricing under fuzzy environments," International Journal of Intelligent Systems, vol. 20, no. 1, pp. 89-102, 2005.

[12] C.-F. Lee, G.-H. Tzeng, and S.-Y. Wang, "A new application of fuzzy set theory to the Black-Scholes option pricing model," Expert Systems with Applications, vol. 29, no. 2, pp. 330-342, 2005.

[13] S. Muzzioli and C. Torricelli, "A multiperiod binomial model for pricing options in a vague world," Journal of Economic Dynamics \& Control, vol. 28, no. 5, pp. 861-887, 2004.

[14] K. A. Chrysafis and B. K. Papadopoulos, "On theoretical pricing of options with fuzzy estimators," Journal of Computational and Applied Mathematics, vol. 223, no. 2, pp. 552-566, 2009.

[15] P. Nowak and M. Romaniuk, "A fuzzy approach to option pricing in a Levy process setting," International Journal of Applied Mathematics and Computer Science, vol. 23, no. 3, pp. 613-622, 2013.

[16] L.-H. Zhang, W.-G. Zhang, W.-J. Xu, and W.-L. Xiao, "The double exponential jump diffusion model for pricing European options under fuzzy environments," Economic Modelling, vol. 29, no. 3, pp. 780-786, 2012. 
[17] W. J. Xu, X. L. Peng, and W. L. Xiao, “The fuzzy jump-diffusion model to pricing European vulnerable options," International Journal of Fuzzy Systems, vol. 15, no. 3, pp. 317-325, 2013.

[18] A. Thavaneswaran, S. S. Appadoo, and J. Frank, "Binary option pricing using fuzzy numbers," Applied Mathematics Letters. An International Journal of Rapid Publication, vol. 26, no. 1, pp. 6572, 2013.

[19] Z.-Y. Feng, J. T.-S. Cheng, Y.-H. Liu, and I.-M. Jiang, "Options pricing with time changed Lévy processes under imprecise information," Fuzzy Optimization and Decision Making, vol. 14, no. 1, pp. 97-119, 2015.

[20] P. Nowak and M. Romaniuk, "Application of Levy processes and Esscher transformed martingale measures for option pricing in fuzzy framework," Journal of Computational and Applied Mathematics, vol. 263, pp. 129-151, 2014.

[21] M. Miyake, H. Inoue, J. Shi, and T. Shimokawa, "A binary option pricing based on fuzziness," International Journal of Information Technology \& Decision Making, vol. 13, no. 6, pp. 1211-1227, 2014.

[22] W.-G. Zhang, W.-L. Xiao, W.-T. Kong, and Y. Zhang, "Fuzzy pricing of geometric Asian options and its algorithm," Applied Soft Computing Journal, vol. 28, pp. 360-367, 2015.

[23] S. S. Appadoo and A. Thavaneswaran, "Recent developments in fuzzy sets approach in option pricing," Journal of Mathematical Finance, vol. 3, no. 2, pp. 312-322, 2013.

[24] E. Agliardi and R. Agliardi, "Fuzzy defaultable bonds," Fuzzy Sets and Systems, vol. 160, no. 18, pp. 2597-2607, 2009.

[25] E. Agliardi and R. Agliardi, "Bond pricing under imprecise information," Operational Research, vol. 11, no. 3, pp. 299-309, 2011.

[26] P. G. Vassiliou, "Fuzzy semi-Markov migration process in credit risk," Fuzzy Sets and Systems, vol. 223, pp. 39-58, 2013.

[27] L. Wu and Y. Zhuang, "A reduced-form intensity-based model under fuzzy environments," Communications in Nonlinear Science and Numerical Simulation, vol. 22, no. 1-3, pp. 1169-1177, 2015.

[28] L. Wu, Y. Zhuang, and X. Lin, "Credit derivatives pricing model for fuzzy financial market," Mathematical Problems in Engineering, vol. 2015, Article ID 879185, 6 pages, 2015.

[29] L. Wu, Y. M. Zhuang, and W. Li, "A new default intensity model with fuzziness and hesitation," International Journal of Computational Intelligence Systems, vol. 9, no. 2, pp. 340-350, 2016.

[30] L. A. Zadeh, "Fuzzy sets," Information and Computation, vol. 8, pp. 338-353, 1965.

[31] H.-C. Wu, "Pricing European options based on the fuzzy pattern of Black-Scholes formula," Computers \& Operations Research, vol. 31, no. 7, pp. 1069-1081, 2004.

[32] A. Kaufmann and M. M. Gupta, Introduction to Fuzzy Arithmetic: Theory and Applications, Von Nostrand Reinhold, New York, NY, USA, 1985.

[33] M. L. Puri and D. A. Ralescu, "Fuzzy random variables," Journal of Mathematical Analysis and Applications, vol. 114, no. 2, pp. 409-422, 1986.

[34] Z.X. Ye and R. X. Zhuang, "Pricing of total return swap," Chinese Journal of Applied Probability and Statistics, vol. 28, no. 1, pp. 7986, 2012.

[35] S. E. Shreve, Stochastic Calculus for Finance II, Springer Finance, Springer-Verlag, New York, NY, USA, 1 edition, 2004.

[36] R. C. Merton, "On the pricing of corporate debt: the risk structure of interest rates," Journal of Finance, vol. 29, no. 2, pp. 449-470, 1974.
[37] S. G. Kou and H. Wang, "First passage times of a jump diffusion process," Advances in Applied Probability, vol. 35, no. 2, pp. 504531, 2003.

[38] R. L. Hao, Pricing credit securities in the contagious model [Ph.D. thesis], Shanghai Jiao Tong University, Shanghai, China, 2011.

[39] D. Dubois and H. Prade, "The mean value of a fuzzy number," Fuzzy Sets and Systems, vol. 24, no. 3, pp. 279-300, 1987.

[40] D. Dubois and H. Prade, Possibility Theory, John Wiley \& Sons, 1988.

[41] C. Carlsson and R. Fullér, "On possibilistic mean value and variance of fuzzy numbers," Fuzzy Sets and Systems, vol. 122, no. 2, pp. 315-326, 2001.

[42] R. Fullér and P. Majlender, "On weighted possibilistic mean and variance of fuzzy numbers," Fuzzy Sets and Systems, vol. 136, no. 3, pp. 363-374, 2003.

[43] A. Wang and Z. Ye, “Total return swap valuation with counterparty risk and interest rate risk," Abstract and Applied Analysis, vol. 2014, Article ID 412890, 12 pages, 2014. 


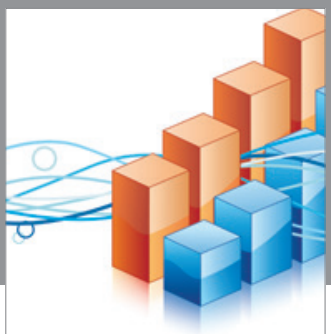

Advances in

Operations Research

vatem alat4

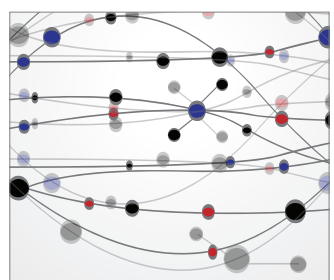

\section{The Scientific} World Journal
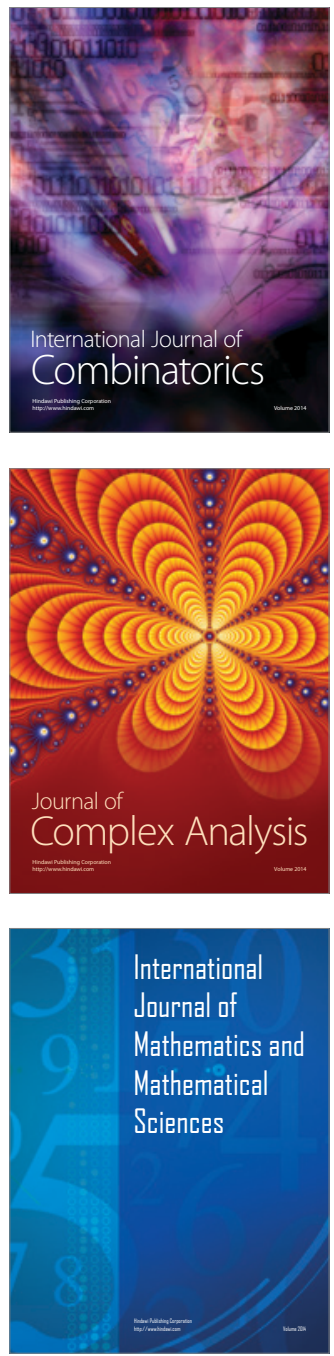
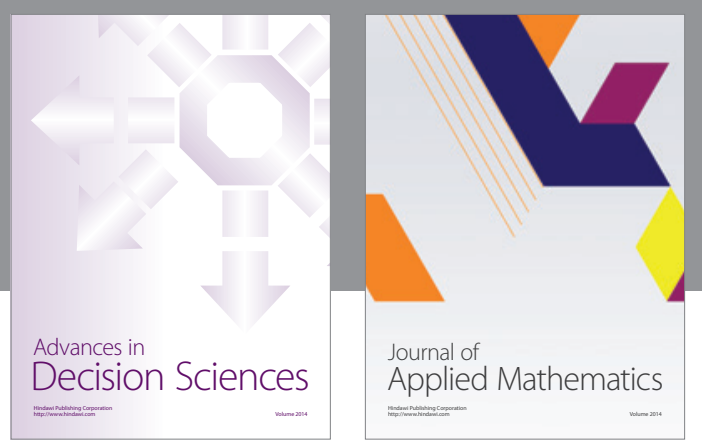

Algebra

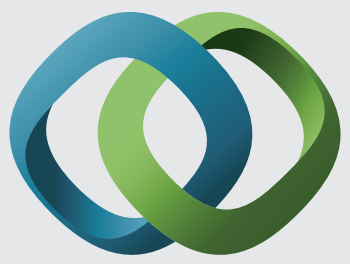

\section{Hindawi}

Submit your manuscripts at

https://www.hindawi.com
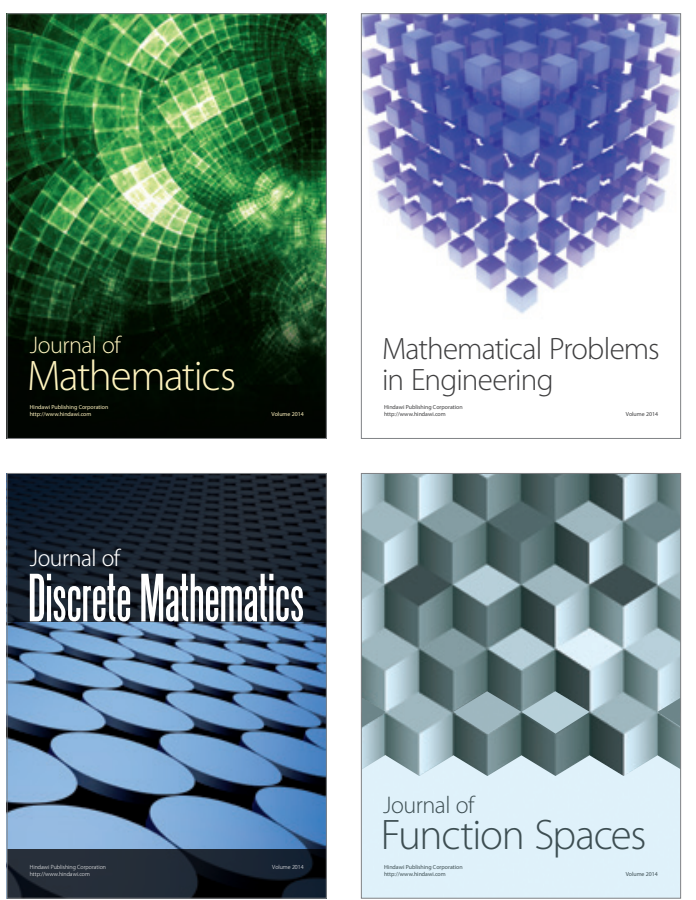

Mathematical Problems in Engineering
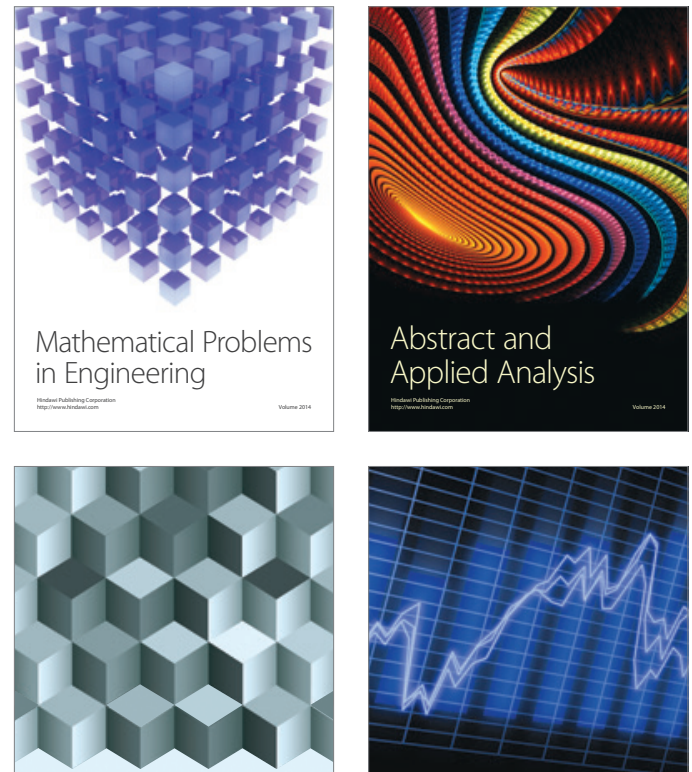

Journal of

Function Spaces

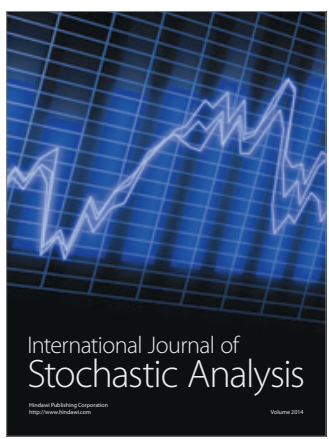

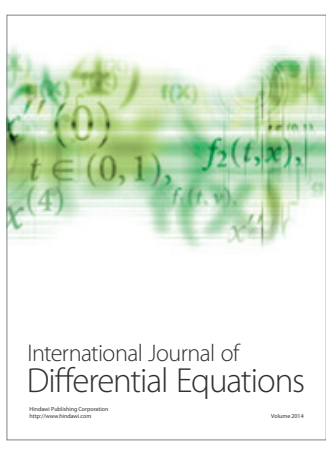
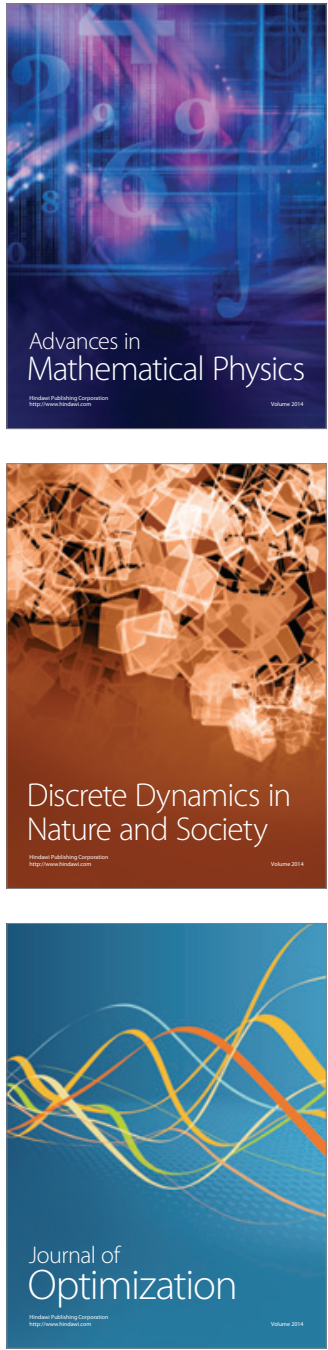